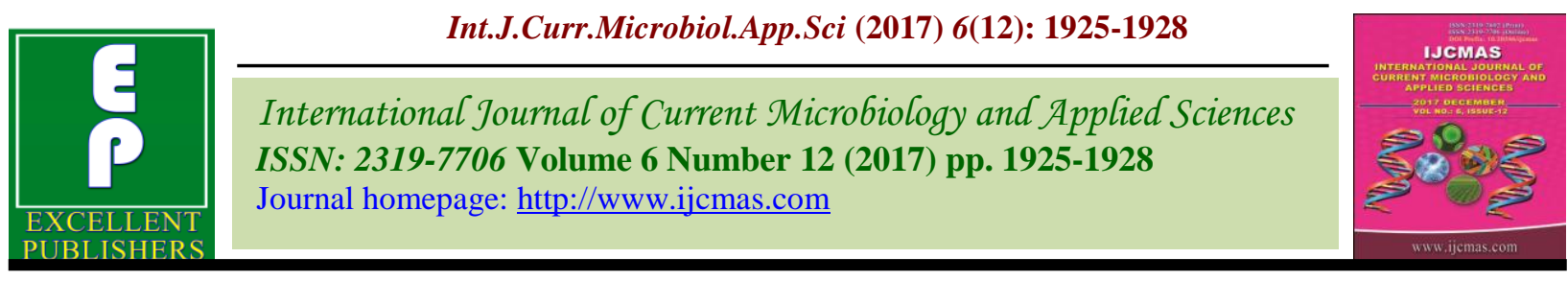

Original Research Article

https://doi.org/10.20546/ijcmas.2017.612.219

\title{
Seroprevalence of Rheumatoid Factor in Arthritis Cases in a Teritiary Care Hospital
}

\author{
S. Chandrasekhar ${ }^{1}$ and Ramalakshmi Koripella ${ }^{2 *}$ \\ ${ }^{1}$ Department of Orthopaedics, ${ }^{2}$ Department of Microbiology, \\ Andhra Medical College, Visakhapatnam, AP, India \\ *Corresponding author
}

A B S T R A C T

\begin{tabular}{|l|}
\hline K e y w o r d s \\
Rheumatoid arthritis, \\
Serological markers, \\
Rheumatoid factor, \\
IgM antibody, \\
Citrullinated peptide \\
antibody.
\end{tabular}

Rheumatoid arthritis is a chronic, severe, progressive inflammatory autoimmune disease of uncertain etiology involving multiple peripheral joints. Rheumatoid arthritis is diagnosed according to clinical findings and serological testing. The main useful serological markers are rheumatoid factor and antibodies to citrullinated peptides. The present study was done to know the prevalence of Rheumatoid factor as a serological marker in clinically suspected arthritis cases in a tertiary care hospital. 100 blood samples from orthopaedic department received in the microbiology department were tested for RF out of 100 patients 68 were females and 32 males. Most of the patients were between the age group $20-50$ years. The prevalence of RF was $7 \%$. Out of 7 RF positive cases 5 were females and 2 were males. Rheumatoid factor alone may be of little value as a screening test to diagnose or exclude rheumatic disease in either healthy populations or those with arthralgias. For evaluation of patients with suspected rheumatoid arthritis it is recommended to perform cyclic citrullinated peptide antibody and $\operatorname{IgM}$ rheumatoid factor to increase both the sensitivity and specificity of the results.

\section{Introduction}

Rheumatoid arthritis is a chronic, severe, progressive inflammatory autoimmune disease of uncertain etiology involving multiple peripheral joints ${ }^{1}$. Rheumatoid arthritis can also produce diffuse inflammation in the lungs, pericardium, pleura, sclera and also nodular lesions most common in the subcutaneous tissue. About $1 \%$ of the world population is afflicted by rheumatoid arthritis and is more common in women than in men and generally occurs between the ages of 40 and 60 years. The disease onset is usually gradual with the predominant symptom being pain, morning stiffness and swelling of many joints ${ }^{2}$. Tends to affect smaller joints of hand and feet early and later on as the disease progresses, symptoms often spread to the knees, ankles, elbows, hips and shoulders. ${ }^{3,4}$

Rheumatoid arthritis is diagnosed according to clinical findings and serological testing. The main useful serological markers are rheumatoid factor and antibodies to citrullinated peptides. Rheumatoid factor (RF) is $\operatorname{IgM}$ antibody directed against the $\mathrm{Fc}$ portion of IgG. It is found in 75 to $80 \%$ of rheumatoid arthritis patients, but has a low specificity because it may be found in healthy elderly individuals and patients with other 
autoimmune disorders or infections. ${ }^{5,6}$ High titre IgM RF is relatively specific for the diagnosis of RA in the context of a chronic polyarthritis, and was for decades the sole serologic criterion widely used in the diagnosis of RA. Rheumatoid factor may have some prognostic value with regard to disease manifestations and activity and the severity of joint erosions. Seropositive RA is often associated with more aggressive joint disease and is more commonly complicated by extra articular manifestations than seronegative RA. The present study was done to know the prevalence of Rheumatoid factor as a serological marker in clinically suspected arthritis cases in a tertiary care hospital.

\section{Materials and Methods}

This prospective study was carried out in the serology section of microbiology department, Andhra Medical College, Visakhapatnam, Andhra Pradesh, India from May 2017 to July 2017.100 blood samples from orthopaedic department received in the serology section of microbiology department were separated into sera and testing was performed.

All the sera were subjected to RF test. Rheumatoid factor-IgM was determined qualitatively and semi quantitatively by latex agglutination assay using RF LATEX Immunopak (Rfckon Diagnostics P Ltd). Interpretation of the results was done as per the kit literature.

\section{Results and Discussion}

Out of 100 patients with clinically diagnosed arthritis 68 were females and 32 were males. Most of the patients were between the age group of 20 to 50 years. The prevalence of rheumatoid factor was $7(7 \%)$. Out of $7 \mathrm{RF}$ positive cases 2 were males and 5 were females. All the positive patients were in the age group of 21-60 (Table 1). Females have a greater predisposition for rheumatoid arthritis than males and out of the 5 positive females four were in the age group of 20-30 years. Both the male positive cases and one female case were in the age group of 50-60 years. All the positive cases showed titres $1 / 16-1 / 28$.

The present study correlates with Sucilathangam et al., (8) who reported $10.6 \%$ of positivity for RF and 8 out of 9 cases were females. Most of the cases were in the age group of 21-60.

Ali Alguweri et al., ${ }^{9}$ reported 97 out of 115 patients were females and median age was 57.5 for males and 48.5 for females. They reported high prevalence of RF which was $81.7 \%$ in their study.

In the recent years it has become clear that early aggressive treatment in rheumatoid arthritis reduces joint damage and improves function. To use a potentially toxic therapy as early as possible we require an accurate diagnosis of RA and also information about prognosis in an individual patient. A part from clinical features, autoantibodies progressive joint damage reflected in radiograph by bone erosion and as joint space narrowing. Since structural joint damage is irreversible, early recognition and treatment are currently being emphasized, with the goal of halting progression of the disease.

The early diagnosis of rheumatoid arthritis is important to prevent crippling. It is important to diagnose RA at a very early stage in the disease, when often not all clinical symptoms are manifest and so good serological markers are needed. ${ }^{10}$

RF was the first auto antibody detected in patients with RA. It was discovered in the early twentieth century and became the primary serological test used in the diagnosis of RA. ${ }^{11}$ 
Table.1 Showing age wise and sex wise distribution of positive cases

\begin{tabular}{|l|l|l|}
\hline Age group & Number of males & Number of females \\
\hline $1-20$ & & \\
\hline $21-30$ & & 4 \\
\hline $31-40$ & & \\
\hline $41-50$ & 1 & \\
\hline $51-60$ & 1 & 1 \\
\hline$>60$ & & \\
\hline
\end{tabular}

In Finland the prevalence of RF positive RA in adults was reported to be $0.7 \%{ }^{12}$. The annual incidence has varied from 32 to 42 per100000 in different studies during the past two decades ${ }^{13}$. A recent study from Finland suggested that daily coffee consumption was associated with an increased prevalence of "False Positive" RF reactions and seemed to be a risk factor for positive RA. ${ }^{14}$

In England the prevalence of a false positive RF reaction was higher in polluted areas than less polluted areas. ${ }^{15}$

The prevalence of RA is $0.5-1 \%$ among adults in Europe but it seems to be much lower in some Asian and African populations. ${ }^{16}$

RF has a low positive predictive value among patients associated with a low prevalence of RF. The positive predictive value of RF was only $24 \%$ for RA and $34 \%$ for any rheumatic disease. On the other hand the negative predictive value of the RF appears to be relatively high $^{17}$

RF positive patients with RA may experience more aggressive and erosive joint disease and extra articular manifestations than those who are RF negative. ${ }^{18,19}$ Similar findings have been observed in juvenile arthritis. ${ }^{20}$

Rheumatoid factor also found in many other diseases, including sjogren's syndrome, systemic lupus erythematosus, mixed connective tissue disease, chronic infection and in healthy elderly population. At present the main clinically useful biologic markers in patients with RA are rheumatoid factors and antibodies to citrullinated peptides for both diagnosis and prediction of functional and radiographic outcomes and ESR and CRP for aiding in ongoing assessment of disease activity and predicting functional and radiographic outcomes.

Rheumatoid factor become part of the classification criteria of RA almost 50 years ago

Rheumatoid factor alone may be of little value as a screening test to diagnose or exclude rheumatic disease in either healthy populations or those with arthralgias. For evaluation of patients with suspected rheumatoid arthritis it is recommended to perform cyclic citrullinated peptide antibody and IgM rheumatoid factor to increase both the sensitivity and specificity of the results.

\section{References}

1. Van Boekel M, Vossenaar ER, van den Hoogen FHJ, van Venrooij WJ. Autoantibody systems in rheumatoid arthritis: sensitivity and diagnostic value. Arthritis Res. 2001; 4: 87-93.

2. Lee DM, Weinblatt ME. Rheumatoid arthritis. Lancet. 2001; 358; 903.

3. Fleming A, Crown JM, Corbett M. Early rheumatoid disease. I. Onset. Ann rheum Dis. 1973; 357.

4. Jacoby RK, Jayson MI, Cosh JA. Onset, early stages, and prognosis of rheumatoid arthritis: a clinical study of 100 patients with 11-year follow up. Br J. 1973; 2:96. 
5. Bartfeld H. Incidence and significance of seropositive tests for rheumatoid factor in non-rheumatoid disease. Ann Intern Med. 1960; 52:1059-1066.

6. Mikkelsen WM, Dodge HJ, Duff IF, Kato $\mathrm{H}$. Estimates of the prevalence of rheumatic diseases in the population of Tecumseh, Michigan, 1959-1960. J Chronic Dis. 1967; 20:351-369.

7. Fahim Khan. The role of rheumatoid factor in the diagnosis of rheumatoid arthritis. www.arthritisandpainclinic.com

8. Sucilathangam, G., G. Smiline, G. Velvizhi and C. Revathy Use of Serological markers for evaluation of patients with Rheumatoid arthritis, International Journal of Current Microbiology and Applied Sciences, Volume 4, 2015.

9. Ali Alghuweri, Ahmed Marafi, Mansour Alhiary. Use of serological markers for evaluation patients with rheumatoid arthritis,Int J Biol Med Res. 2012; 3(1): 1397-1398

10. Vossenaar, E.R., Venrooij, W.J.V. 2004. Anti- CCP antibodies, a highly specific marker for (early) rheumatoid arthritis.Clin. Appl. Immunol. Rev., 4(4): 239262.

11. Renaudineau, Y., Jamin, C., Saraux, A., Youinou, P. 2005. Rheumatoid factor on a daily basis.Autoimmunity, 38(1): 11-6.

12. Aho K, Heliövaara M, Sievers K, Maatela J, Isomäki H. Clinical arthritis associated with positive radiological and serological findings in Finnish adults. Rheumatol Int., 1989; 9:7.

13. Isomäki $\mathrm{H}$, Raunio $\mathrm{J}$, von Essen $\mathrm{R}$, Hämeenkorpi R. Incidence of inflammatory rheumatic diseases in
Finland. Scand J Rheumatol 1978; 7: 188-92.

14. Lawrence JS, Locke GB, Ball J. Rheumatoid serum factor in populations in the U.K. I. Lung disease and rheumatoid serum factor. ClinExp Immunol., 1971; 8: 723-39.

15. Heliövaara $\mathrm{M}$, Aho $\mathrm{K}$, Knekt $\mathrm{P}$, Impivaara $\mathrm{O}$, Reunanen $\mathrm{A}$, Aromaa A. Coffee consumption, rheumatoid factor, and the risk of rheumatoid arthritis. Ann Rheum Dis., 2000; 59: 631-5.

16. Silman AJ. Rheumatoid arthritis. In: Silman AJ, Hochberg MC, eds. Epidemiology of the rheumatic diseases. 2nd ed. Oxford: Oxford University Press, 2001: 31-71.

17. Shmerling, RH, Delbanco, TL. How useful is the rheumatoid factor? An analysis of sensitivity, specificity, and predictive value. Arch Intern Med., 1992; 152: 2417.

18. Van der Heijde, DM, van Riel, PL, van Rijswijk, MH, van de Putte, LB. Influence of prognostic features on the final outcome in rheumatoid arthritis: A review of the literature. Semin Arthritis Rheum 1988; 17: 284.

19. Cats, A, Hazevoet, HM. Significance of positive tests for rheumatoid factor in the prognosis of rheumatoid arthritis. A follow-up study. Ann Rheum Dis 1970; 29:254.

20. Aggarwal, A, Dabadghao, S, Naik, S, Misra, R. Serum IgM rheumatoid factor by enzyme-linked immunosorbent assay (ELISA) delineates a subset of patients with deforming joint disease in seronegative juvenile rheumatoid arthritis. Rheumatol. Int., 1994; 14:135.

\section{How to cite this article:}

Chandrasekhar, S. and Ramalakshmi Koripella. 2017. Seroprevalence of Rheumatoid Factor in Arthritis Cases in a Teritiary Care Hospital. Int.J.Curr.Microbiol.App.Sci. 6(12): 1925-1928. doi: https://doi.org/10.20546/ijcmas.2017.612.219 